\title{
Activated Carbons Based on Shea Nut Shells (Vitellaria paradoxa): Optimization of Preparation by Chemical Means Using Response Surface Methodology and Physicochemical Characterization
}

\author{
Liouna Adoum Amola1, Theophile Kamgaing1, Donald Raoul Tchuifon Tchuifon ${ }^{1,2}$, \\ Cyrille Donlifack Atemkeng ${ }^{1}$, Solomon Gabche Anagho ${ }^{*}$
}

${ }^{1}$ Laboratory of Noxious Chemistry and Environmental Engineering, Department of Chemistry, University of Dschang, Dschang, Cameroon

${ }^{2}$ Department of Chemical Engineering and Process Engineering, National Higher Polytechnic School of Douala, University of Douala, Douala, Cameroon

Email: *sg_anagho@yahoo.com

How to cite this paper: Amola, L.A., Kamgaing, T., Tchuifon, D.R.T., Atemkeng, C.D. and Anagho, S.G. (2020) Activated Carbons Based on Shea Nut Shells (Vitellaria paradoxa): Optimization of Preparation by Chemical Means Using Response Surface Methodology and Physicochemical Characterization. Journal of Materials Science and Chemical Engineering, 8, 53-72.

https://doi.org/10.4236/msce.2020.88006

Received: July 19, 2020

Accepted: August 28, 2020

Published: August 31, 2020

Copyright $\odot 2020$ by author(s) and Scientific Research Publishing Inc. This work is licensed under the Creative Commons Attribution International License (CC BY 4.0).

http://creativecommons.org/licenses/by/4.0/

\section{(c) (i) Open Access}

\begin{abstract}
In this study, shea residues (Vitellaria paradoxa) dumped in the wild by the units processing almonds into butter were used in the production of activated carbons. Shea nut shells harvested in the locality of Baktchoro, West Tandjile Division of Chad were used as a precursor for the preparation of activated carbons by chemical activation with phosphoric acid $\left(\mathrm{H}_{3} \mathrm{PO}_{4}\right)$ and sulphuric acid $\left(\mathrm{H}_{2} \mathrm{SO}_{4}\right)$. Central Composite Design (CCD) was used to optimize the preparation conditions, and the factors used were concentration of activating agent $(1-5 \mathrm{M})$, carbonization temperature $\left(400^{\circ} \mathrm{C}-700^{\circ} \mathrm{C}\right)$ and residence time $(30-120 \mathrm{~min})$. The studies showed that at optimal conditions the yield was $51.45 \%$ and $42.35 \%$, while the iodine number (IN) was 709.45 and 817.36 $\mathrm{mg} / \mathrm{g}$ for CAK-P (phosphoric acid activated carbon) and CAK-S (sulphuric acid activated carbon) respectively. These two activated carbons (ACs) which were distinguished by their considerable iodine number, were variously characterized by elementary analysis, $\mathrm{pH}$ at the point of zero charge (pHpzc), bulk density, moisture content, Boehm titration, Fourier transform infrared spectroscopy, BET adsorption and scanning electron microscopy. These analyses revealed the acidic and microporous nature of CAK-P and CAK-S carbons, which have a specific microporous surface area of 522.55 and 570.65 $\mathrm{m}^{2} \cdot \mathrm{g}^{-1}$ respectively.
\end{abstract}




\section{Keywords}

Residue, Shea Nuts, Activated Carbon, Optimization, Central Composite Design

\section{Introduction}

A major environmental problem facing agro-food industries is their inability to efficiently manage the residues and by-products generated during the primary processing of raw materials. On the industrial scale, the processing of agricultural commodities generates huge quantities of lignocellulosic residues that are disposed of by land filling or incineration. These practices have a negative effect on man and his environment. For example, open-air incineration generates substances which are toxic to humans and constitute greenhouse gases that have damaging effects on the climate [1]. It is because they are wrongly considered as wastes that these agricultural residues are treated in this way.

A large quantity of these lignocellulose residues can be recycled by fermenting them to generate methane which is a fuel, and ethanol which is both a solvent and a fuel [2]. They can also be composted to obtain an enriched soil conditioner, which can improve soil fertility. Furthermore, a controlled pyrolysis of these lignocellulosic wastes produces activated carbons [3]. Of these alternative treatments of the lignocellulosic residues, the transformation into activated carbons is more flexible; with chemical activation significantly reducing the energy cost of the process.

Activated carbons are carbon-based materials, found in granulated or black powdered form, and having a porous structure with very large surface areas. Amongst other applications, they are used in air filtration systems, purifying contaminated water, deodourization, dechlorination, and in gold mining operations [4]. They are also used as catalysts or catalyst support [4]. A lot of research has been carried out to synthesize activated carbons from lignocellulosic precursors. These precursors include corn shells [3], sunflower seed shells [5], Flamboyant (Delonix regia) pods [6], cotton cakes [7], rice hulls [8], coconut shells [1], garcinia cola pods [9] and olive stones [10].

It is in the quest for sustainable development that the recycling of agricultural and industrial waste, especially shea residues (Vitellaria paradoxa), arouses particular interest. Socioeconomically, shea is valuable in that its butter has medicinal, food and cosmetic values [11], and it is relatively abundant in many African countries. In the Republic of Chad, for example, shea industries produce 556,000 tonnes of almonds per year [12]. While the nuts are used for butter production, nut shells, the more woody part of the fruit could be used as a raw material for the production of activated carbons. This alternative use of the nut shells has the advantage that, on the economic domain, value has been added onto the wastes; on the perspective of environmental pollution, the generation of 
greenhouse gases is avoided or highly minimised; and finally concerning sanitation the generation of pollutants harmful to man is avoided.

The objective of this research was to optimize the preparation of activated carbons using shea hulls as precursor. The process optimization was carried out using Response Surface Methodology (RSM), applying the Central Composite Design (CCD) in order to obtain maximum information with minimal experiments [13].

\section{Materials and Methods}

\subsection{Preparation of Activated Carbon}

\section{Materials}

The shea nut shells (CNK) (Figure 1) collected in Baktchoro in the West Tandjilé Division in Chad were washed with tap water to remove the remaining pulp and other forms of attached impurities. They were dehydrated by drying in an oven set at $105^{\circ} \mathrm{C}$ for 24 hours.

Finally, they were crushed and sieved to obtain particles of size $0.5-2 \mathrm{~mm}$ that were preserved for use in this study.

\section{Preparation of activated carbons}

$20 \mathrm{~g}$ of CNK was impregnated by mixing it with $40 \mathrm{~mL}$ solutions of phosphoric acid $\left(\mathrm{H}_{3} \mathrm{PO}_{4}\right)$ or sulphuric acid $\left(\mathrm{H}_{2} \mathrm{SO}_{4}\right)$ of concentrations ranging from 1 to $5 \mathrm{~mol} \cdot \mathrm{L}^{-1}$. After stirring for 24 hours to ensure reaction between the activating agent and the $\mathrm{CNK}$, the mixture was then filtered and the filtrate dried in an oven at $105^{\circ} \mathrm{C}$ for 1 hour to obtain the impregnated material. In each case, the impregnated materials was pyrolysed in a furnace of mark HERAEUS that was set at temperatures ranging from $400^{\circ} \mathrm{C}$ to $700^{\circ} \mathrm{C}$ for residence times of 30 to 120 minutes, and a constant heating rate of $6^{\circ} \mathrm{C} \cdot \mathrm{min}^{-1}$. The residue from filtering the mixture was thoroughly washed with distilled water to remove the residual acid and then dried in a Binder oven set at $105^{\circ} \mathrm{C}$ to obtain the activated carbon.

\subsection{Determination of Yield and Iodine Number (IN) of Activated Carbons}

The yield of activated carbon was determined as the mass of the dried activated carbon relative to the mass of the precursor, and given by the Equation (1):

$$
\text { Yield }=\frac{\text { Mass of activated carbon obtained }}{\text { Mass of Shea nut shell }} \times 100
$$

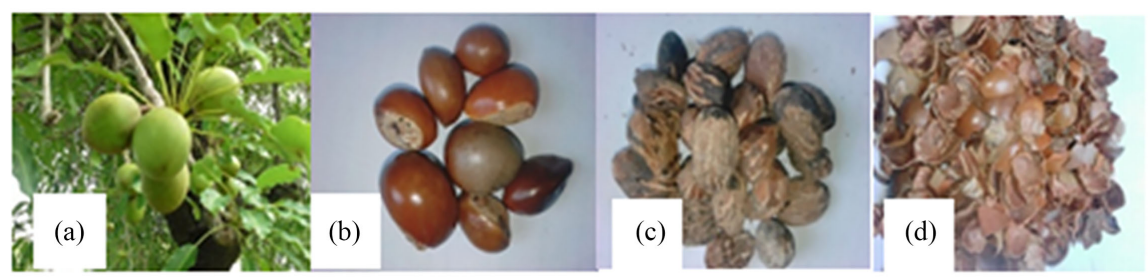

Figure 1. Photograph of shea (Vitellaria paradoxa): (a) tree and fruit, (b) seeds, (c) nuts and (d) walnut shells. 


\section{Iodine Number (IN)}

The iodine number of the activated carbons was determined using the procedure established by the American Society for Testing and Materials (ASTM) [14]. This was done by mixing $100 \mathrm{mg}$ of activated carbon with $30 \mathrm{~mL}$ of iodine solution of concentration $0.01 \mathrm{~mol} \cdot \mathrm{L}^{-1}$ in a sealed bottle. The mixture was stirred away from the sun rays at a speed of $200 \mathrm{rpm}$ for 3 hours. The resulting mixture was quickly filtered using filter paper, and $10 \mathrm{~mL}$ of filtrate was titrated with a solution of sodium thiosulfate pentahydrate $\left(\mathrm{Na}_{2} \mathrm{~S}_{2} \mathrm{O}_{3} \cdot 5 \mathrm{H}_{2} \mathrm{O}\right)$, of concentration $0.005 \mathrm{~N}$, using starch solution as indicator. From the chemical reaction given in Equation (2), Equation (3) was deduced and used to determine the amount of iodine adsorbed, thereby giving the iodine number (IN).

$$
\begin{array}{r}
2 \mathrm{Na}_{2} \mathrm{~S}_{2} \mathrm{O}_{3}(\mathrm{aq})+\mathrm{I}_{2}(\mathrm{aq}) \rightarrow \mathrm{Na}_{2} \mathrm{~S}_{4} \mathrm{O}_{6}(\mathrm{aq})+2 \mathrm{NaI}(\mathrm{aq}) \\
Q_{I_{2}}=\frac{\left(C_{0}-\frac{C_{t h} V_{t h}}{2 V_{I_{2}}}\right) 2 M_{I_{2}} \cdot V_{\text {ads }}}{m_{C A}}
\end{array}
$$

$Q_{I_{2}} \quad\left(\mathrm{mg} \cdot \mathrm{g}^{-1}\right)$ is the mass of iodine adsorbed per gram of adsorbent; $m_{C A}(\mathrm{~g})$ the mass of activated carbon; $C_{0}\left(\mathrm{~mol} \cdot \mathrm{L}^{-1}\right)$ the initial concentration of $\mathrm{I}_{2}$ solution; $C_{t h}\left(\mathrm{~mol} \cdot \mathrm{L}^{-1}\right)$ the concentration of sodium thiosulfate; $V_{t h}(\mathrm{~mL})$ the volume of sodium thiosulfate; $V_{a d s}(\mathrm{~mL})$, the volume of iodine solution that was mixed with the activated carbon; $V_{I_{2}}(\mathrm{~mL})$ the volume of iodine solution titrated and $M_{I_{2}}\left(\mathrm{~g} \cdot \mathrm{mol}^{-1}\right)$ the molar mass of $\mathrm{I}_{2}$.

\subsection{Optimizing the Preparation of Activated Carbons}

\section{Experimental design: response surface methodology}

The preparation of ACs was optimized through Response Surface Methodology. Central Composite Design was chosen to generate the experimental matrix in order to reduce the number of experiments to be performed while simultaneously studying the effects of several factors [15] [16]. Thus, the total number of experiments performed was calculated from Equation (4) given below [17].

$$
N=2^{k}+2 k+k_{c}
$$

$N$ is the total number of experiments, 2 indicates the number of levels per factor, $k$ the number of factors studied, $2^{k}$ the number of factor points, $2 k$ the number of axial points and $k_{c}$ the number of points in the center that determined errors or reproducibility of the data.

Based on literature [18] and on previously conducted tests in our laboratory [19], the factors that significantly influence the physical properties of activated carbons are the concentration of activating agents $\left(X_{1}\right)$, the carbonization temperature $\left(X_{2}\right)$ and residence time $\left(X_{3}\right)$. In this work, $\mathrm{H}_{3} \mathrm{PO}_{4}$ and $\mathrm{H}_{2} \mathrm{SO}_{4}$ were used as activating agents. Table 1 presents the independent experimental variables used as calculated from Equation (5) [17] [20]. The values of the experimental variables were coded as follows: -1 for the small value, 0 the value at the centre and +1 the high value. 
Table 1. Independent experimental variables.

\begin{tabular}{cccc}
\hline & \multicolumn{3}{c}{ Coded level } \\
\cline { 2 - 4 } Experimental factors & -1 & 0 & +1 \\
\cline { 2 - 4 } & \multicolumn{3}{c}{ Actual level } \\
\hline Concentration of activating agent: $X_{1}\left(\mathrm{~mol} \cdot \mathrm{L}^{-1}\right)$ & 1 & 3 & 5 \\
Carbonization temperature: $X_{2}\left({ }^{\circ} \mathrm{C}\right)$ & 400 & 550 & 700 \\
Carbonization time: $X_{3}(\mathrm{~min})$ & 30 & 75 & 120 \\
\hline
\end{tabular}

$$
a_{i}=\frac{A_{i}-A_{0}}{\Delta A}
$$

$a_{i}$ is the value of an independent variable, $A_{i}$ the actual value of a variable $i$, $A_{0}$ the value of the variable at the center point and $\Delta A$ is the step change.

To assess quantitatively and qualitatively the activated carbons obtained, the mass yield and iodine number were used as responses or performance indicators. The second order polynomial Equation (6) was used to evaluate the interactions between the factors [20] [21].

$$
Y=\alpha_{0}+\sum_{i=1}^{n} \alpha_{i} x_{i}+\sum_{i=1}^{n} \alpha_{i i} x_{i}^{2}+\sum_{i=1}^{n} \sum_{j=1}^{n} \alpha_{i j} x_{i} x_{j}+\varepsilon
$$

$Y$ is the predicted response, $x_{i}$ and $x_{j}$ are the coded values of the factors, $\alpha_{0}, \alpha_{i}, \alpha_{i i}$ and $\alpha_{i j}$ are the regression coefficients for intercept, linear, quadratic and interaction terms respectively and $\varepsilon$ the uncertainty between measured and predicted values.

\section{Validating the statistical model}

The empirical model obtained was validated using Statgraphic plus 5.0 software as the evaluation instrument. The model was regarded as good when the experimental values obtained were close to those predicted by the t-test and p-value. When the t-test value was high and the p-value small, then, the correlation coefficient was high. In general, a model was valid when $R^{2}$ was greater than $75 \%$ and the p-value was $5 \%$ or less (with 95\% confidence level) [16].

\subsection{Characterization of Activated Carbons Prepared at the Optimal Conditions}

The activated carbons prepared at the optimal conditions were characterized by various physicochemical methods. These optimal conditions were those provided by the Statgraphic plus 5.0 software; and they were the concentration of activating agents, the carbonization temperature and residence time, that led to high values of iodine number.

\subsubsection{EDX Analysis}

Elementary analysis using energy dispersion X-ray spectrometry was applied to investigate the presence and percentage of atoms that made up the activated carbons. 


\subsubsection{Bulk Density}

To measure the bulk density, a mass of activated carbon was carefully poured into a graduated and previously weighed $25 \mathrm{~cm}^{3}$ volumetric flask. The difference in mass $m_{A C}$ compared to the occupied volume $\left(V_{o c}\right)$ was used to calculate the apparent density as follows:

$$
d_{a p p}=\frac{m_{A C}}{V_{o c}}
$$

\subsubsection{Moisture Content}

To determine the moisture level, an empty and well dried porcelain crucible was weighed $\left(m_{0}\right)$ using a precision scale of $1 / 1000 \mathrm{~b}$ and $1 \mathrm{~g}$ of activated carbon was properly distributed on it and weighed again $\left(m_{1}\right)$. The combination consisting of crucible and activated carbon was then placed in the oven set at $100^{\circ} \mathrm{C}$ for 1 hour. After cooling to room temperature, the system is again weighed $\left(m_{2}\right)$. The humidity, $\mathrm{T}$ was calculated by the relationship (8) [22]:

$$
T \%=\frac{m_{1}-m_{2}}{m_{1}-m_{0}} \times 100
$$

\subsection{4. $\mathrm{pH}$ and $\mathrm{pH}$ at the Point of Zero Charge ( $\left.\mathrm{pH}_{\mathrm{PzC}}\right)$}

The $\mathrm{pH}$ of the ACs was obtained by putting $30 \mathrm{~mL}$ of distilled water and $100 \mathrm{mg}$ of AC in contact in a wash-bottle. The mixture was agitated for 24 hours; decanted, and the $\mathrm{pH}$ of the solution was measured using an ATC-mark $\mathrm{pH}$-meter.

The $\mathrm{pH}$ at the point of zero charge $\left(\mathrm{pH}_{\mathrm{pzc}}\right)$ was determined according to the protocol described by Tchakala et al., (2012) [7]. In washed bottles containing 30 $\mathrm{mL}$ of sodium chloride $(\mathrm{NaCl})$ solution of concentration $0.1 \mathrm{~mol} \cdot \mathrm{L}^{-1}$, the $\mathrm{pH}$ was adjusted from 2 to 10 using $0.1 \mathrm{~mol} \cdot \mathrm{L}^{-1}$ solution of hydrochloric acid $\mathrm{HCl}$ or 0.1 mol. $\mathrm{L}^{-1}$ sodium hydroxide $\mathrm{NaOH}$ to obtain the initial values $\mathrm{pH}_{\mathrm{i}}$.

$100 \mathrm{mg}$ of activated carbon was introduced into each bottle and the mixture stirred for 24 hours. After leaving the mixtures to settle, the final $\mathrm{pH}$ values, $\mathrm{pH}_{\mathrm{f}}$ were measured. The $\mathrm{pH}_{\mathrm{pzc}}$ was obtained as the intersection of the curve: $\mathrm{pH}_{\mathrm{f}}=f\left(\mathrm{pH}_{\mathrm{i}}\right)$ and the bisector of the first quadrant.

\subsubsection{Specific Surface Area}

The porous structure of the ACs was determined by nitrogen adsorption at 77.13 $\mathrm{K}$. This measurement was made using a sorptophotometric porosimeter (Thermo Electron Corporation Advanced Data Processing). The B.E.T method (Brunauer, Emmett and Teller) was used to determine the specific surface of the samples. The total pore volume $V_{T}$ is the volume of liquid nitrogen adsorbed at the relative pressure $\left(P / P_{0}\right)$ of 0.005 to 0.4 [1]. Thus, from the B.E.T method coupled with the B.J.H. (Barret-Joyner-Halenda) the distribution of pore size, and consequently the microporous volume, $V_{\text {micro }}$, mesoporous volume, $V_{\text {meso }}$ and the average pore diameter, $D_{p}$ were calculated [23].

\subsubsection{Quantification of Functional Surface Groups}

The quantification of surface functional groups was carried out using the Boehm method (1966) [24]. To do this, $0.1 \mathrm{~g}$ of activated carbon in $30 \mathrm{~mL}$ of a solution 
of $\mathrm{NaHCO}_{3}\left(0.1 \mathrm{~mol} \cdot \mathrm{L}^{-1}\right)$, or $\mathrm{Na}_{2} \mathrm{CO}_{3}\left(0.1 \mathrm{~mol} \cdot \mathrm{L}^{-1}\right)$ or $\mathrm{NaOH}\left(0.1 \mathrm{~mol} \cdot \mathrm{L}^{-1}\right)$ was agitated at room temperature for 48 hours to determine the acid groups, or with $30 \mathrm{~mL}$ of $\mathrm{HCl}\left(0.1 \mathrm{~mol} \cdot \mathrm{L}^{-1}\right)$ to determine the basic groups. The filtrates were titrated with $\mathrm{HCl}\left(0.1 \mathrm{~mol} \cdot \mathrm{L}^{-1}\right)$ or $\mathrm{NaOH}\left(0.1 \mathrm{~mol} \cdot \mathrm{L}^{-1}\right)$, depending on whether acid or basics groups were concerned; and in the presence of an indicator. The calculation was based on the principle that $\mathrm{NaHCO}_{3}$ neutralizes carboxylic acid groups, $\mathrm{Na}_{2} \mathrm{CO}_{3}$ neutralizes carboxylic and lactone groups and $\mathrm{NaOH}$ neutralizes carboxylic, lactone and phenolic groups and the basic groups are neutralized in their entirety by $\mathrm{HCl}$. The number of equivalents (meq. $\mathrm{g}^{-1}$ ) and the type of functional groups were determined from the relationship (9) [22]:

$$
\eta_{\text {eqg }}=N_{0} V_{0}-N_{f} V_{0}
$$

where, $\eta_{\text {eqg }}$ is the number of gram equivalents that reacted, while $N_{0} V_{0}$ and $N_{f} V_{0}$ are the number of gram equivalents before and after reaction.

\subsubsection{Fourier-Transform Infrared Spectroscopy (IR-TF)}

A Thermoscientific Nicolet iS5 brand spectrophotometer was used to investigate the chemical functional groups present on the surface of the activated carbons. The IR-TF spectra were recorded between the wavenumbers 3500 and $580 \mathrm{~cm}^{-1}$.

\subsubsection{Scanning Electron Microscopy (SEM)}

In order to study surface morphology and verify the porosity of the adsorbents, samples of the prepared activated carbons were examined by the PHILIPS XL30 S-FEG scanning electron microscope (SEM) equipped with a spectrometer that uses a cathode luminescence detector. Samples of each activated carbon prepared under the conditions of the best iodine number were selected for the SEM analysis.

\section{Results and Discussion}

\subsection{Experimental Design Using the Central Composite Design}

The central composite design was used with the aim of finding the optimal conditions for the preparation of activated carbon in a short time. Mass yield and iodine number were chosen as responses of the factors influencing $\left(X_{1}, X_{2}\right.$ and $\left.X_{3}\right)$ the preparation of the activated carbons. The results of the experimental matrix are presented in Table 2. Repetitive experiments 7, 8 and 11 were used to verify the reproducibility of the data during handling.

\subsubsection{Iodine Number}

The iodine number of carbon CAK-P (phosphoric acid activated carbon) and CAK-S (sulphuric acid activated carbon) is an important parameter which provides information on their microporosity. The results of the iodine number are presented in Table 2. Experimental values of the iodine number range from 301.95 to $655.81 \mathrm{mg} \cdot \mathrm{g}^{-1}$ and between 419.10 and $781.05 \mathrm{mg} \cdot \mathrm{g}^{-1}$ respectively for CAK-P and CAK-S. The mathematical models of the quadratic regression used to predict the optimal iodine number values are $Y_{2}$ and $Y_{4}$ for CAK-P and CAK-S respectively (Equations (10) and (11)): 
Table 2. Experimental design matrix for CAK-P and CAK-S preparation using central composite design (CCD).

\begin{tabular}{|c|c|c|c|c|c|c|c|}
\hline \multirow{2}{*}{$\begin{array}{l}\text { 1) } \mathrm{H}_{3} \mathrm{PO}_{4} \\
\text { activation }\end{array}$} & \multicolumn{3}{|c|}{ CAK-P preparation parameters } & \multicolumn{2}{|c|}{$\begin{array}{c}\text { Yield (\%) } \\
Y_{1}\end{array}$} & \multicolumn{2}{|c|}{$\begin{array}{c}\mathrm{IN}\left(\mathrm{mg} \cdot \mathrm{g}^{-1}\right) \\
Y_{2}\end{array}$} \\
\hline & $X_{1}\left(\mathrm{~mol} \cdot \mathrm{L}^{-1}\right)$ & $X_{2}\left({ }^{\circ} \mathrm{C}\right)$ & $X_{3}(\min )$ & Exp. Val. ${ }^{\mathrm{a}}$ & Pred. Val. ${ }^{\mathrm{b}}$ & Exp. Val. ${ }^{a}$ & Pred. Val. ${ }^{\mathrm{b}}$ \\
\hline 1 & $1(-1)$ & $400(-1)$ & $120(+1)$ & 40.99 & 40.52 & 301.95 & 264.46 \\
\hline 2 & $3(0)$ & $400(-1)$ & $75(0)$ & 43.96 & 45.07 & 446.25 & 415.06 \\
\hline 3 & $5(+1)$ & $550(0)$ & $75(0)$ & 43.34 & 42.80 & 570.55 & 550.79 \\
\hline 4 & $3(0)$ & $700(+1)$ & $75(0)$ & 36.43 & 35.84 & 457.22 & 491.45 \\
\hline 5 & $1(-1)$ & $700(+1)$ & $120(+1)$ & 33.74 & 34.56 & 361.95 & 365.85 \\
\hline 6 & $1(-1)$ & $550(0)$ & $75(0)$ & 40.67 & 41.74 & 371.47 & 394.29 \\
\hline 7 & $3(0)$ & $550(0)$ & $75(0)$ & 41.47 & 40.98 & 438.15 & 436.15 \\
\hline 8 & $3(0)$ & $550(0)$ & $75(0)$ & 41.33 & 40.98 & 438.15 & 436.15 \\
\hline 9 & $5(+1)$ & $700(+1)$ & $120(+1)$ & 38.43 & 38.77 & 655.81 & 612.59 \\
\hline 10 & $1(-1)$ & $700(+1)$ & $30(-1)$ & 38.16 & 37.22 & 655.81 & 624.12 \\
\hline 11 & $3(0)$ & $550(0)$ & $75(0)$ & 41.21 & 40.98 & 438.30 & 436.15 \\
\hline 12 & $5(+1)$ & $700(+1)$ & $30(-1)$ & 36.06 & 36.40 & 486.25 & 522.97 \\
\hline 13 & $5(+1)$ & $400(-1)$ & $120(+1)$ & 42.66 & 43.46 & 647.70 & 678.61 \\
\hline 14 & $1(-1)$ & $400(-1)$ & $30(-1)$ & 51.45 & 50.97 & 369.00 & 405.33 \\
\hline 15 & $5(+1)$ & $400(-1)$ & $30(-1)$ & 49.84 & 48.88 & 476.25 & 471.58 \\
\hline 16 & $3(0)$ & $550(0)$ & $120(+1)$ & 40.06 & 38.56 & 381.01 & 426.87 \\
\hline 17 & $3(0)$ & $550(0)$ & $30(-1)$ & 40.56 & 42.59 & 495.30 & 452.49 \\
\hline $\begin{array}{l}\text { 2) } \mathrm{H}_{2} \mathrm{SO}_{4} \\
\text { activation }\end{array}$ & \multicolumn{3}{|c|}{ CAK-S preparation parameters } & \multicolumn{2}{|c|}{$\begin{array}{c}\text { Yield (\%) } \\
Y_{3}\end{array}$} & \multicolumn{2}{|c|}{$\begin{array}{c}\mathrm{IN}\left(\mathrm{mg} \cdot \mathrm{g}^{-1}\right) \\
Y_{4}\end{array}$} \\
\hline Nun order & $X_{1}\left(\mathrm{~mol} \mathrm{~L}^{-1}\right)$ & $X_{2}\left({ }^{\circ} \mathrm{C}\right)$ & $X_{3}(\min )$ & Exp. Val. ${ }^{\text {a }}$ & Pred. Val. ${ }^{b}$ & Exp.Val. a & Pred. Val. ${ }^{\mathrm{b}}$ \\
\hline 1 & $1(-)$ & $400(-)$ & $120(+)$ & 40.75 & 40.20 & 590.55 & 651.31 \\
\hline 2 & $3(0)$ & $400(-)$ & $75(0)$ & 39.21 & 39.73 & 438.15 & 561.91 \\
\hline 3 & $5(+)$ & $550(0)$ & $75(0)$ & 38.65 & 38.36 & 609.60 & 632.69 \\
\hline 4 & $3(0)$ & $700(+)$ & $75(0)$ & 35.28 & 35.54 & 762.00 & 758.61 \\
\hline 5 & $1(-)$ & $700(+)$ & $120(+)$ & 36.44 & 36.18 & 781.05 & 760.38 \\
\hline 6 & $1(-)$ & $550(0)$ & $75(0)$ & 37.88 & 39.93 & 678.65 & 675.93 \\
\hline 7 & $3(0)$ & $550(0)$ & $75(0)$ & 38.32 & 37.77 & 685.80 & 676.18 \\
\hline 8 & $3(0)$ & $550(0)$ & $75(0)$ & 38.15 & 37.77 & 666.75 & 676.18 \\
\hline 9 & $5(+)$ & $700(+)$ & $120(+)$ & 34.08 & 33.93 & 781.05 & 772.15 \\
\hline 10 & $1(-)$ & $700(+)$ & $30(-)$ & 39.73 & 39.53 & 685.80 & 699.62 \\
\hline 11 & $3(0)$ & $550(0)$ & $75(0)$ & 38.41 & 37.77 & 676.75 & 676.18 \\
\hline 12 & $5(+)$ & $700(+)$ & $30(-)$ & 37.32 & 37.67 & 704.85 & 713.99 \\
\hline 13 & $5(+)$ & $400(-)$ & $120(+)$ & 40.90 & 40.91 & 514.35 & 550.44 \\
\hline 14 & $1(-)$ & $400(-)$ & $30(-)$ & 40.97 & 40.92 & 419.11 & 527.92 \\
\hline 15 & $5(+)$ & $400(-)$ & $30(-)$ & 41.95 & 42.02 & 419.10 & 429.67 \\
\hline 16 & $3(0)$ & $550(0)$ & $120(+)$ & 36.13 & 37.07 & 678.65 & 721.37 \\
\hline 17 & $3(0)$ & $550(0)$ & $30(-)$ & 39.47 & 39.30 & 742.95 & 630.60 \\
\hline
\end{tabular}

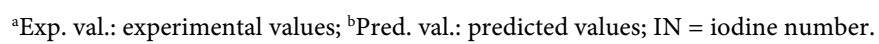




$$
\begin{aligned}
Y_{2}= & 329.721-11.2223 X_{1}+0.162766 X_{2}-1.05419 X_{3} \\
& +9.0987 X_{1}^{2}-0.1395 X_{1} X_{2}+0.966389 X_{1} X_{3} \\
& +0.000760 X_{2}^{2}-0.004348 X_{2} X_{3}+0.001745 X_{3}^{2} \\
Y_{4}= & 66.049-29.0745 X_{1}+1.32658 X_{2}+2.32076 X_{3} \\
& -5.46871 X_{1}^{2}+0.093858 X_{1} X_{2}-0.007277 X_{1} X_{3} \\
& -0.000707 X_{2}^{2}-0.002319 X_{2} X_{3}-0.000098 X_{3}^{2}
\end{aligned}
$$

Table 3 summarizes the analysis of variance (ANOVA) performed to deter-

\begin{tabular}{|c|c|c|c|c|c|c|c|}
\hline \multirow{2}{*}{ Source } & \multirow{2}{*}{ Df } & \multicolumn{3}{|c|}{ Yield (\%) } & \multicolumn{3}{|c|}{$\mathrm{IN}\left(\mathrm{mg} \cdot \mathrm{g}^{-1}\right)$} \\
\hline & & MS & F-value & p-value & MS & F-value & p-value \\
\hline \multicolumn{8}{|c|}{ 1) $\mathrm{H}_{3} \mathrm{PO}_{4}$ activation (CAK-P) } \\
\hline$X_{1}$ & 1 & 2.8302 & 1.45 & 0.2671 & $61,227.50$ & 27.79 & $0.0012^{*}$ \\
\hline$X_{2}$ & 1 & 212.3370 & 109.06 & $0.0000^{*}$ & $14,588.60$ & 6.62 & $0.0368^{\star}$ \\
\hline$X_{3}$ & 1 & 40.7636 & 20.94 & $0.0026^{*}$ & 1640.96 & 0.74 & 0.4167 \\
\hline$X_{1} X_{1}$ & 1 & 4.4673 & 2.29 & 0.1736 & 3548.88 & 1.61 & 0.2450 \\
\hline $\mathrm{X}_{1} X_{2}$ & 1 & 0.8001 & 0.41 & 0.5419 & $14,011.40$ & 6.36 & $0.0397^{\star}$ \\
\hline$X_{1} X_{3}$ & 1 & 12.6756 & 6.51 & $0.0380^{*}$ & $60,517.20$ & 27.47 & $0.0012^{*}$ \\
\hline$X_{2} X_{2}$ & 1 & 0.7209 & 0.37 & 0.5621 & 784.34 & 0.36 & 0.5695 \\
\hline$X_{2} X_{3}$ & 1 & 30.3810 & 15.60 & $0.0056^{\star}$ & 6891.38 & 3.13 & 0.1203 \\
\hline$X_{3} X_{3}$ & 1 & 0.4367 & 0.22 & 0.6502 & 33.4765 & 0.02 & 0.9054 \\
\hline Residual Error & 7 & 1.9471 & & & 2203.29 & & \\
\hline \multicolumn{5}{|c|}{$R^{2}=95.71 \%$ adj $R^{2}=89.20 \%$} & \multicolumn{3}{|c|}{$R^{2}=91.64 \%$ adj $R^{2}=80.88 \%$} \\
\hline Source & Df & MS & F-value & p-value & MS & F-value & p-value \\
\hline \multicolumn{8}{|c|}{ 2) $\mathrm{H}_{2} \mathrm{SO}_{4}$ activation (CAK-S) } \\
\hline$X_{1}$ & 1 & 0.8237 & 1.5 & 0.2608 & 4674.68 & 6.85 & $0.0346^{*}$ \\
\hline$X_{2}$ & 1 & 43.8065 & 79.58 & $0.0000^{*}$ & $96,725.30$ & 141.69 & $0.0000^{*}$ \\
\hline$X_{3}$ & 1 & 12.41 & 22.54 & $0.0021^{*}$ & $20,597.10$ & 30.17 & $0.0009^{*}$ \\
\hline$X_{1} X_{1}$ & 1 & 2.0579 & 3.74 & 0.0944 & 1282.04 & 1.88 & 0.2129 \\
\hline$X_{1} X_{2}$ & 1 & 4.3513 & 7.90 & $0.0261^{\star}$ & 6342.76 & 9.29 & $0.0186^{*}$ \\
\hline$X_{1} X_{3}$ & 1 & 0.0761 & 0.14 & 0.7211 & 3.4322 & 0.01 & 0.9455 \\
\hline$X_{2} X_{2}$ & 1 & 0.05524 & 0.10 & 0.7607 & 679.46 & 1.00 & 0.3517 \\
\hline$X_{2} X_{3}$ & 1 & 3.4585 & 6.28 & $0.0406^{*}$ & 1960.63 & 2.87 & 0.1340 \\
\hline$X_{3} X_{3}$ & 1 & 0.4535 & 0.82 & 0.3943 & 0.1070 & 0.00 & 0.9904 \\
\hline Residual Error & 7 & 0.5505 & & & 682.655 & & \\
\hline \multicolumn{5}{|c|}{$R^{2}=94.75 \% ;$ adj $R^{2}=88.01 \%$} & \multicolumn{3}{|c|}{$R^{2}=96.57 \% ;$ adj $R^{2}=92.17 \%$} \\
\hline
\end{tabular}
mine the variables that interact significantly during the production of the activated carbons. It appears that the experimental values and predicted values are in agreement, since the determination coefficients $R^{2}$ of this are close to unity for the two activated carbons ( $R^{2}=91.64 \%$ for CAK-P and $R^{2}=96.57$ for CAK-S).

Table 3. Analysis of variance (ANOVA) for the regression mode IN and Yield.

${ }^{*}$ Significant; $\mathrm{Df}=$ degree of freedom; $\mathrm{MS}=$ mean square; $\mathrm{IN}=$ iodine number; $\operatorname{adj} \mathrm{R}^{2}=\operatorname{adjusted} \mathrm{R}^{2}$. 
Referring to the probable p-values $\leq 0.05$, the terms $X_{1}, X_{2}, X_{1} X_{2}$ and $X_{1} X_{3}$ for CAK-P and $X_{1}, X_{2}, X_{3}$ and $X_{1} X_{2}$ for CAK-S have values less than the said probability $\mathrm{p}$, which shows that all these terms are significant. Therefore, temperature and concentration have a significant effect on the iodine number. This is confirmed by the Pareto diagram analysis shown in Figure 2(a) and Figure 2(b) which clearly leave the corresponding bands cut by a vertical test line. Figure 2(c) and Figure 2(d) show the response surface obtained according to concentration and temperature with a fixed time of 75 minutes. The examination of this figure shows that the iodine number increase with the increase in activation temperature. This is because when the temperature rises, the volatile materials evaporate and some pores are enlarged while more pores are created [25], thus increasing the sites for adsorption [18].

In general, the increase in the concentration of activating agents leads to an increase in the iodine number. Tagne et al. (2019) [16] also reported similar results. For soft lignocellulosic precursors, a high concentration of activating agent leads to less porous activated carbon, which leads to a reduction in the iodine number due to the destruction and/or absence of the appearance of pores. However, the combined action of high concentration and high temperature increase the pores of activated carbon, thereby leading to high iodine number values, as can be seen with experiment 9 in this work.

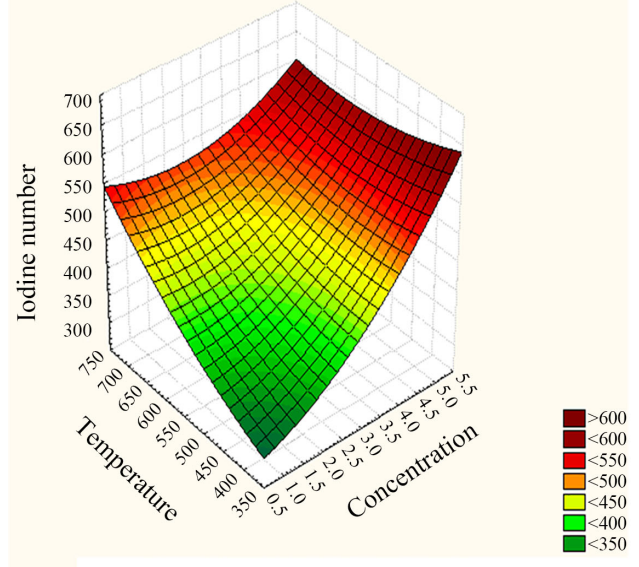

(a)

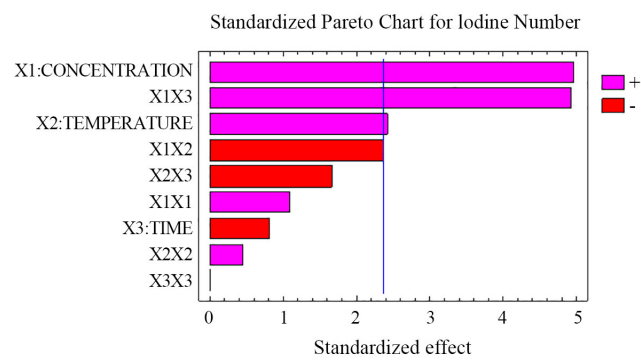

(c)

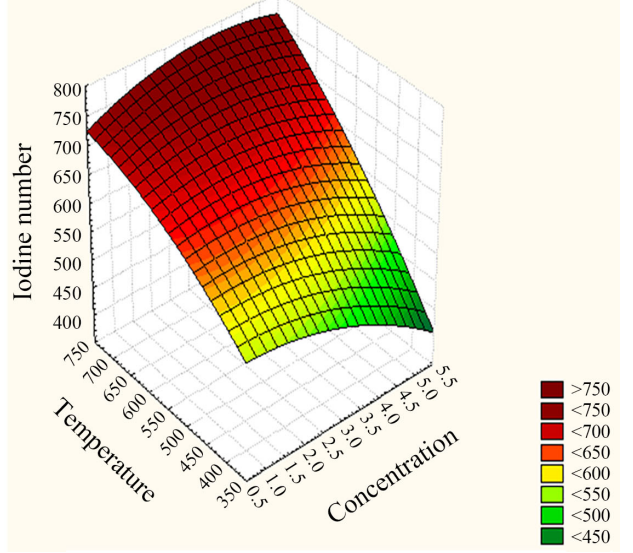

(b)

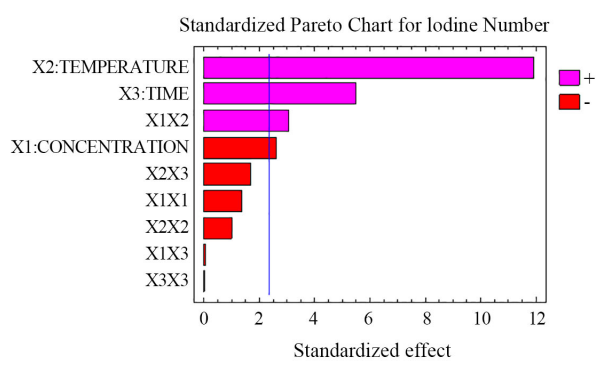

(d)

Figure 2. Response surfaces: CAK-P (a), CAK-S (b) and Pareto diagrams: CAK-P (c), CAK-S (d) for iodine number. 


\subsubsection{Activated Carbon Yield}

The outcome from the production process of activated carbon is the yield. The performance values shown in Table 2 range from $33.74 \%-51.45 \%$ and $34.08 \%$ $41.95 \%$ respectively for CAK-P and CAK-S. The yield is seen to decrease as the temperature increases. The yields are also seen to be high at low residence time and high concentration of the activating agent, as evidenced by experiment 15 (Table 2). The mathematical models of CAK-P $\left(Y_{1}\right)$ and CAK-S $\left(Y_{3}\right)$ are given by Equations (12) and (13).

$$
\begin{aligned}
Y_{1}= & 72.0488-3.299650 X_{1}-0.030175 X_{2}-0.215706 X_{3} \\
& +0.322817 X_{1}^{2}+0.001054 X_{1} X_{2}+0.013986 X_{1} X_{3} \\
& -0.000023 X_{2}^{2}-0.000288 X_{2} X_{3}-0.000199 X_{3}^{2} \\
Y_{3}= & 40.604-0.024779 X_{1}+0.007747 X_{2}+0.001594 X_{3} \\
& +0.219102 X_{1}^{2}-0.002458 X_{1} X_{2}-0.001083 X_{1} X_{3} \\
& -0.000006 X_{2}^{2}-0.000097 X_{2} X_{3}+0.000203 X_{3}^{2}
\end{aligned}
$$

The results of the ANOVA show that the terms $X_{2}, X_{3}, X_{1} X_{3}$ and $X_{2} X_{3}$ are significant for the CAK-P and $X_{2}, X_{3}, X_{1} X_{2}$ and $X_{2} X_{3}$ are significant for CAK-S. According to Figure $3(\mathrm{c})$ and Figure $3(\mathrm{~d})$, an increase in carbonization temperature leads to a decrease in yield, while the concentration of activating agents and the residense time have a less significant effect on the response. This decrease in yield can be attributed to the fact that an increase in the calcination temperature increases the amount of carbon combusted and the continued release of volatile material, as is reflected by the loss of material from the precursor. The maximum yield was achieved when the carbonization temperature and residence time were maintained at their lowest values. The results obtained are consistent with those of the literature [18] [26] and it can be concluded that temperature has a greater impact on yield compared to the concentration of activating agents and the time of calcination on the performance of CAK-P and CAK-S.

\subsubsection{Process Optimization and Test Validation}

The optimal conditions for the production of the activated carbons were deduced from the maximum yield values and the iodine number. The experimental values of the responses were analyzed by Statgraphic plus 5.0 software and the results are presented in Table 4. We observe that the experimental values are close to the predicted values, implying that the difference between these two values is not significant. However, it is not easy to simultaneously meet the optimal performance and iodine number requirements provided by this software for the preparation of better activated carbons because the zone of interest of the factors is different. The same remark was made by Lekene et al. (2018) [18]. The activated carbons prepared under optimal conditions using iodine number were consequently characterized. At the residence time of $120 \mathrm{~min}$, the optimal conditions obtained were $5 \mathrm{~mol} \cdot \mathrm{L}^{-1}$ of $\mathrm{H}_{3} \mathrm{PO}_{4}$ and $400^{\circ} \mathrm{C}$ carbonization temperature for CAK-P; and $3.5 \mathrm{~mol} \cdot \mathrm{L}^{-1}$ of $\mathrm{H}_{2} \mathrm{SO}_{4}$ and $700^{\circ} \mathrm{C}$ for CAK-S. 


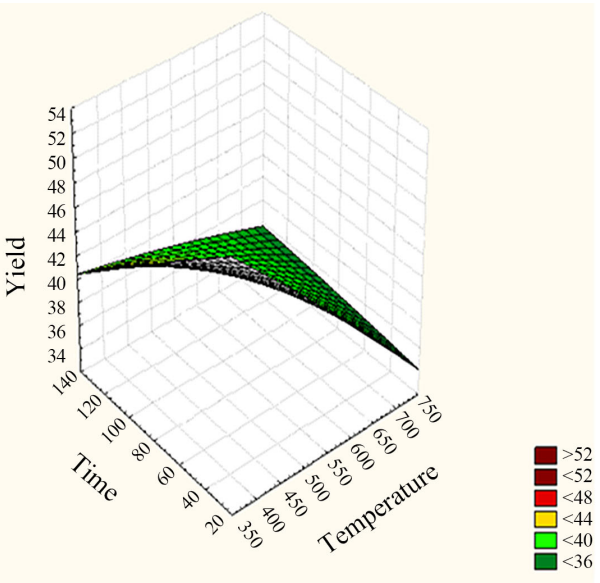

(a)

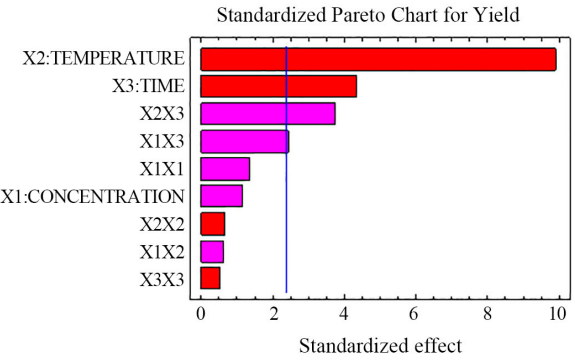

(c)

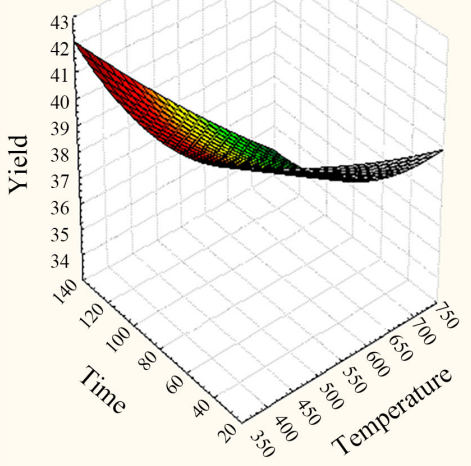

(b)

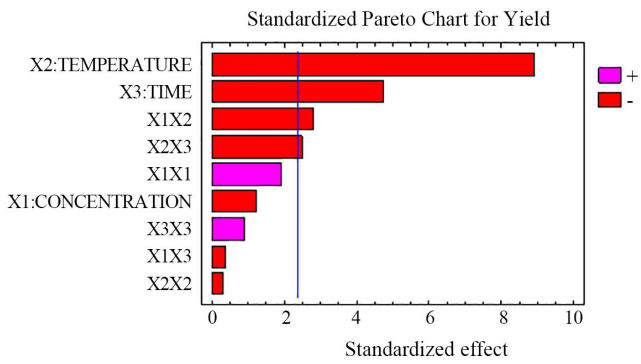

(d)

Figure 3. Response Surfaces: CAK-P (a), CAK-S (b) and Pareto diagrams: CAK-P (c), CAK-S (d) for Yield.

Table 4. Validation of the experimental model.

\begin{tabular}{|c|c|c|c|c|c|}
\hline \multirow{2}{*}{$\begin{array}{c}\text { Activated } \\
\text { Carbons }\end{array}$} & \multirow{2}{*}{\multicolumn{2}{|c|}{ Preparation factors }} & \multicolumn{3}{|c|}{ IN $\left(\mathrm{mg} \cdot \mathrm{g}^{-1}\right)$} \\
\hline & & & \multirow{2}{*}{$\begin{array}{c}\text { Experimental } \\
\text { value }\end{array}$} & \multirow{2}{*}{$\begin{array}{l}\text { Predicted } \\
\text { value }\end{array}$} & \multirow{2}{*}{ Residue } \\
\hline & $X_{1}\left(\mathrm{~mol} \cdot \mathrm{L}^{-1}\right)$ & 5 & & & \\
\hline \multirow[t]{3}{*}{ CAK-P } & $X_{2}\left({ }^{\circ} \mathrm{C}\right)$ & 400 & 709.45 & 678.61 & 30.84 \\
\hline & $X_{3}(\min )$ & 120 & & & \\
\hline & $X_{1}\left(\mathrm{~mol} \cdot \mathrm{L}^{-1}\right)$ & 3.50 & & & \\
\hline \multirow[t]{4}{*}{ CAK-S } & $X_{2}\left({ }^{\circ} \mathrm{C}\right)$ & 700 & 817.36 & 788.38 & 28.98 \\
\hline & $X_{3}(\min )$ & 120 & & & \\
\hline & & & \multicolumn{3}{|c|}{ Yield (\%) } \\
\hline & $X_{1}\left(\mathrm{~mol} \cdot \mathrm{L}^{-1}\right)$ & 1 & & & \\
\hline \multirow[t]{3}{*}{ CAK-P } & $X_{2}\left({ }^{\circ} \mathrm{C}\right)$ & 400 & 51.45 & 50.97 & 0.48 \\
\hline & $X_{3}(\min )$ & 30 & & & \\
\hline & $X_{1}\left(\mathrm{~mol} \cdot \mathrm{L}^{-1}\right)$ & 5 & & & \\
\hline \multirow[t]{2}{*}{ CAK-S } & $X_{2}\left({ }^{\circ} \mathrm{C}\right)$ & 400 & 42.35 & 42.02 & 0.33 \\
\hline & $X_{3}(\min )$ & 30 & & & \\
\hline
\end{tabular}




\subsection{Physical Characteristics}

\subsubsection{EDX Analysis}

EDX analysis of the activated carbons is shown in Figure 4 while Table 5 gives the weight percentages of the elements present in them. This analysis was coupled with the scanning electron microscopy (SEM/EDX) captured on a selected area 1 section of the SEM image. Carbon appears to be the most representative element in CAK-P and CAK-S, this is explained by the increase in the degree of aromatization during carbonization. The small amounts of the other elements originated from the lignocellulosic precursor, and they become perceptible on the departure of volatile substances during carbonization.

\subsubsection{Physico-Chemical Characteristics of the Activated Carbons: $\mathrm{pH}$, pHpzc, Bulk Density, Moisture Content and Boehm Titration}

The physico-chemical properties that were determined for the prepared ACs are presented in Table 6. The $\mathrm{pH}$ values of 3.34 and 6.91 respectively for CAK-P and CAK-S show that the two activated carbons are acidic. pHpzc values are 2.23 and 6.9 respectively for CAK-P and CAK-S (Table 6, Figure 5). These are the $\mathrm{pH}$ values where the two carbons exist at zero electrical potential. This means that for solutions where $\mathrm{pH}>\mathrm{pHpzc}$, the electrostatic attraction is favourable for the cationic pollutant because the surface of the material is deprotonated. On the other hand, when $\mathrm{pH}<\mathrm{pHpzc}$, the electrostatic attraction is favourable for the anionic pollutant since the surface of the material is protonated [27].

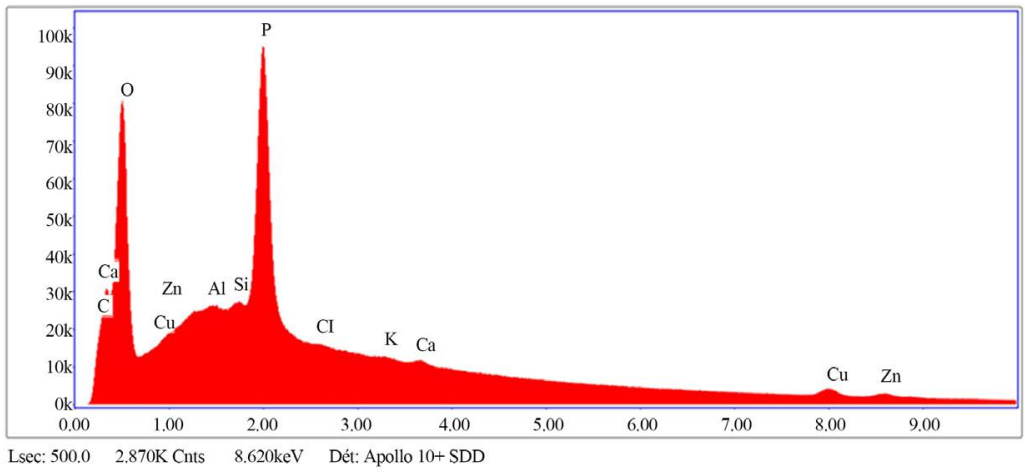

(a)

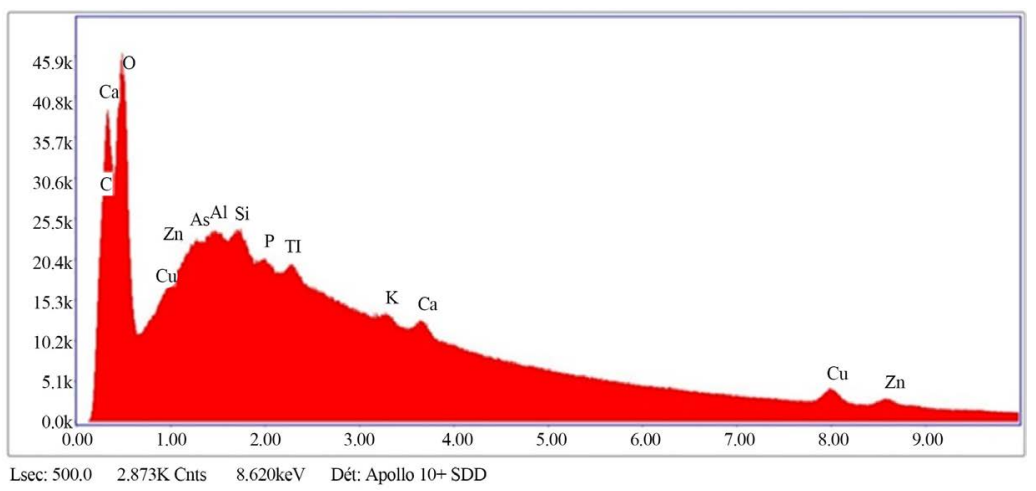

(b)

Figure 4. EDX analysis of activated carbons: CAK-P (a) and CAK-S (b). 


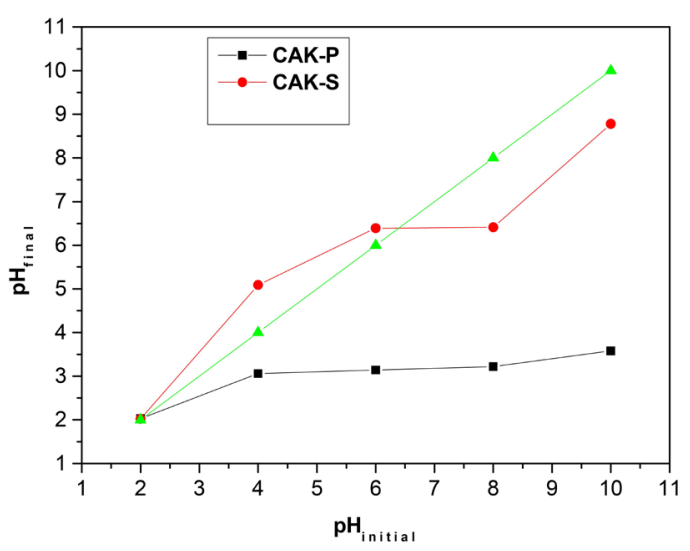

Figure 5. Determination of the $\mathrm{pH}$ at the point of zero charge (pHpzc) for CAK-P and CAK-S.

Table 5. Elemental content of the activated carbons in percentage.

\begin{tabular}{ccccccccccccc}
\hline Elements & $\mathrm{C}$ & $\mathrm{O}$ & $\mathrm{As}$ & $\mathrm{Al}$ & $\mathrm{Si}$ & $\mathrm{P}$ & $\mathrm{Ti}$ & $\mathrm{Cl}$ & $\mathrm{K}$ & $\mathrm{Ca}$ & $\mathrm{Cu}$ & $\mathrm{Zn}$ \\
\hline CAK-P & 44.87 & 43.71 & $/$ & 0.87 & 0.80 & 7.82 & $/$ & 0.21 & 0.06 & 0.13 & 0.89 & 0.64 \\
CAK-S & 53.49 & 41.44 & 0.20 & 0.34 & 0.52 & 0.20 & 0.09 & $/$ & 0.27 & 0.51 & 1.69 & 1.24 \\
\hline
\end{tabular}

Table 6. Some physico-chemical characteristics of CAK-P and CAK-S.

\begin{tabular}{cccccc}
\hline & $\mathrm{pH}$ & $\mathrm{pH}_{\mathrm{pzc}}$ & $\begin{array}{c}\text { Moisture } \\
\text { content }(\%)\end{array}$ & $\begin{array}{c}\text { Bulk density } \\
\left(\mathrm{g} \cdot \mathrm{cm}^{-3}\right)\end{array}$ & \\
\hline CAK-P & 3.34 & 2.23 & 5.00 & 0.796 & \\
CAK-S & 6.91 & 6.37 & 4.62 & 0.849 & \\
\hline Quantification of surface functions by Boehm titration $\left(\right.$ meq $\left.^{-1}\right)$ & & \\
\hline CAK-P & Carboxylic & Lactone & Phenol & Total acid & Total base \\
CAK-S & 0.09 & 0.18 & 0.03 & 0.3 & 0 \\
\hline
\end{tabular}

The bulk density of an activated carbon provides information on the microcristalline structure and strong inter-linking bonds [28]. The moisture content of these ACs is in line with the standard of $\leq 5 \%$ as stipulated by the American Work and Water Society.

\subsubsection{Specific Surface Area}

The textural structure of the activated carbons was determined by the BET method, using relative pressure $\left(\mathrm{P} / \mathrm{P}_{0}\right)$ from 0.005 to 0.4. Figure 6 and Figure 7 show the analyses on porosity for CAK-P and CAK-S respectively. According to the classification of IUPAC and taken up by Francisco et al. (2018) [29], the adsorption and desorption isotherm of $\mathrm{N}_{2}$ is Type I and $\mathrm{H} 4$ hysteresis illustrates the coexistence of micropores and mesopores. The result shows that these two activated carbons have more micropores than mesopores. The results are summarized in Table 7. The measurement of specific surfaces according to the Bru- 
nauer-Emmett-Teller analysis (BET) yielded $457.38 \mathrm{~m}^{2} \cdot \mathrm{g}^{-1}$ and $490.62 \mathrm{~m}^{2} \cdot \mathrm{g}^{-1} \mathrm{re}-$ spectively for CAK-P and CAK-S. Thus the microporous surfaces are 522.55 $\mathrm{m}^{2} \cdot \mathrm{g}^{-1}$ and $570.56 \mathrm{~m}^{2} \cdot \mathrm{g}^{-1}$ and the mesoporous ones are $9.1974 \mathrm{~m}^{2} \cdot \mathrm{g}^{-1}$ and 10.779 $\mathrm{m}^{2} \cdot \mathrm{g}^{-1}$ respectively for CAK-P and CAK-S. Therefore, the two activated carbons have a similar texture, but the one activated with sulphuric acid has better developed pores. In view of these results it is obvious that these ACs can be used to adsorb small and medium-sized molecules from aqueous solution. Table 7 shows the values obtained.

Table 7. Summary report of micrometrics analysis for CAK-P and CAK-S.

\begin{tabular}{|c|c|c|c|c|c|c|c|c|c|}
\hline & \multirow{2}{*}{$\begin{array}{c}S_{B E T} \\
\mathrm{~m}^{2} \cdot \mathrm{g}^{-1}\end{array}$} & \multirow{2}{*}{$\begin{array}{l}\text { Volume } \\
\text { total } \\
\mathrm{cm}^{3} \cdot \mathrm{g}^{-1}\end{array}$} & \multicolumn{3}{|c|}{ Micropores } & \multicolumn{3}{|c|}{ Mesopores } & \multirow{2}{*}{$\begin{array}{c}\text { Hysteresis } \\
\text { type }\end{array}$} \\
\hline & & & $\begin{array}{c}S_{\text {micro }} \\
\mathrm{m}^{2} \cdot \mathrm{g}^{-1}\end{array}$ & $\begin{array}{c}V_{\text {micro }} \\
\mathrm{cm}^{3} \cdot \mathrm{g}^{-1}\end{array}$ & $D_{p} \mathrm{~nm}$ & $\begin{array}{c}S_{\text {meso }} \\
\mathrm{m}^{2} \cdot \mathrm{g}^{-1}\end{array}$ & $\begin{array}{c}V_{\text {meso }} \\
\mathrm{cm}^{3} \cdot \mathrm{g}^{-1}\end{array}$ & $D_{p} \mathrm{~nm}$ & \\
\hline CAK-P & 457.38 & 105.08 & 522.55 & 0.17 & 0.30 & 9.19 & 0.01 & 2.24 & $\mathrm{~F}$ \\
\hline CAK-S & 490.62 & 112.72 & 570.56 & 0.18 & 0.29 & 10.77 & 0.01 & 2.16 & \\
\hline
\end{tabular}

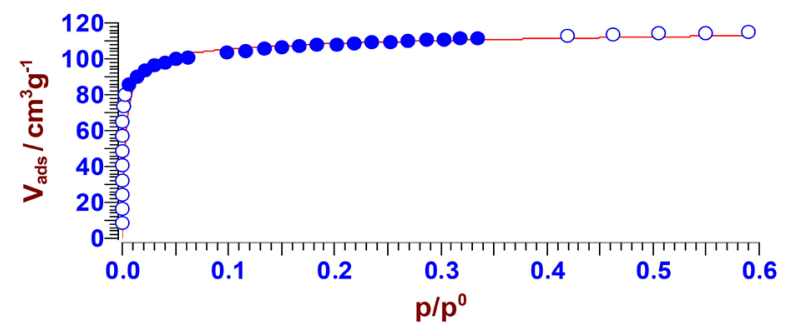

(a)

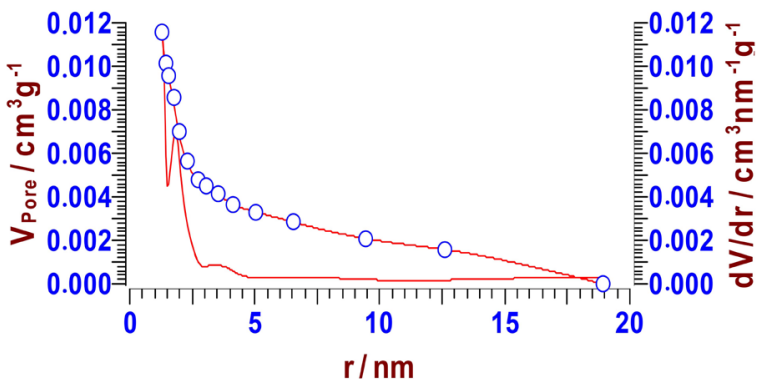

(b)

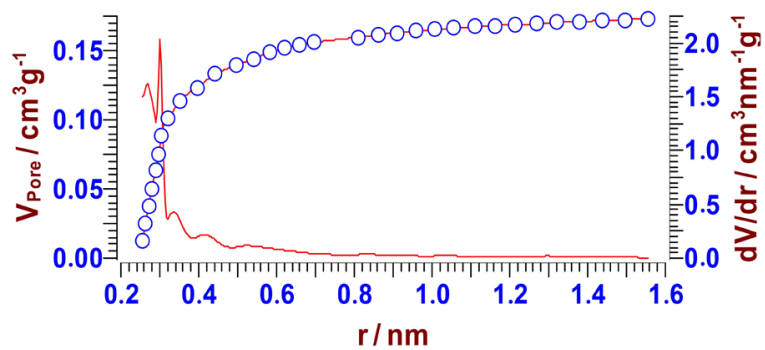

(c)

Figure 6. CAK-P: Adsorption-desorption curves of nitrogen at $77.13 \mathrm{~K}$ (a), Sample mesopores (b) and micropores (c) Size distribution. 


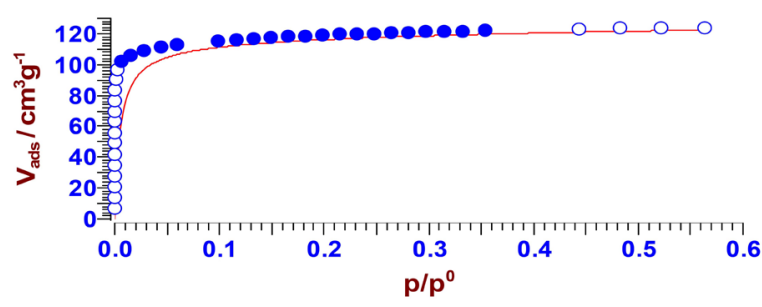

(a)

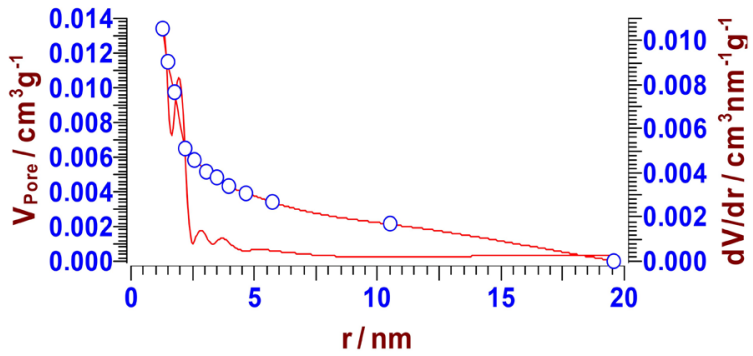

(b)

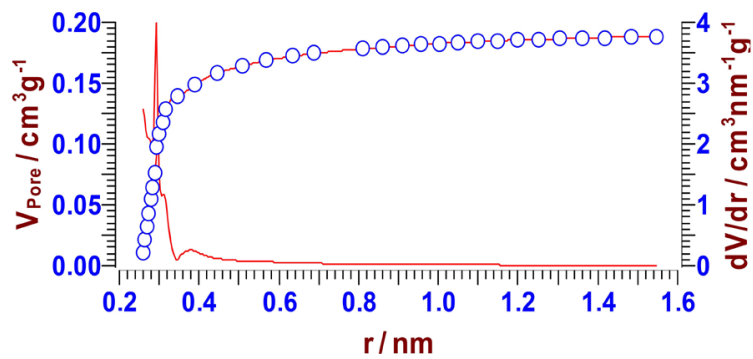

(c)

Figure 7. CAK-S: Adsorption-desorption curves of nitrogen at $77.13 \mathrm{~K}$ (a), Sample mesopores (b) and micropores (c) Size distribution.

\subsubsection{FTIR Spectra}

Figure 8 shows the IR-TF spectra recorded in the 3500 to $580 \mathrm{~cm}^{-1}$ region. Low peaks at 2915.36 and $2861.41 \mathrm{~cm}^{-1}$ on the biomass spectrum (CNK) indicate the symmetric and asymmetric stretching vibration of methyl group [18] [28]. The absence of these peaks on the spectra of the CAK-P and CAK-S activated carbons shows that during the activation with phosphoric and sulphuric acids, there was a reaction resulting in the formation of other oxygenated functional groups. The signal at $2368.65 \mathrm{~cm}^{-1}$ may be due to O-C-O and the peak at $1731.65 \mathrm{~cm}^{-1}$ corresponds to the $\mathrm{C}-\mathrm{O}$ group of esters and lactones. The appearance of the peak at $1040.36 \mathrm{~cm}^{-1}$ corresponds to the $\mathrm{C}-\mathrm{O}$ group of primary, secondary, tertiary alcohols and ethers, while that at $1257.96 \mathrm{~cm}^{-1}$ indicates the presence of the same group $\mathrm{C}-\mathrm{O}$ group of carboxylic acids and esters or the $\mathrm{P}-\mathrm{O}$ link of ester phosphates or O-C of the P-O-C bridge [1]. Between 800 and $650 \mathrm{~cm}^{-1}$ we have the $\mathrm{C}-\mathrm{H}$ bond of aromatic polynuclear systems [30].

\subsubsection{Scanning Electron Microscopy (SEM) Analysis}

The results obtained from the SEM analyses of the activated carbons are presented in Figure 9. These pictures show that the two activated carbons have 


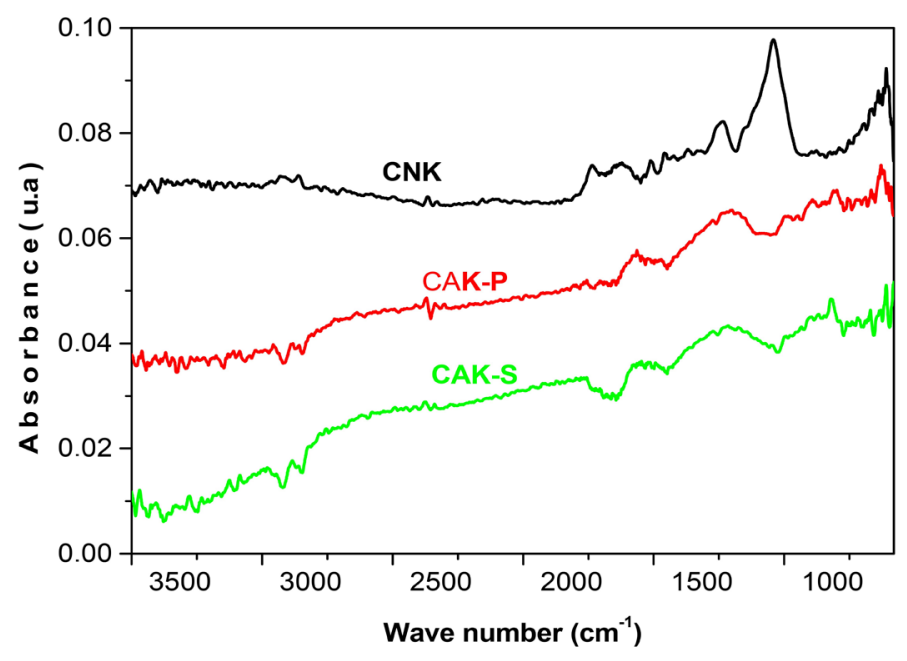

Figure 8. FTIR spectra for biomass (CNK) and activated carbons (CAK-P and CAK-S).

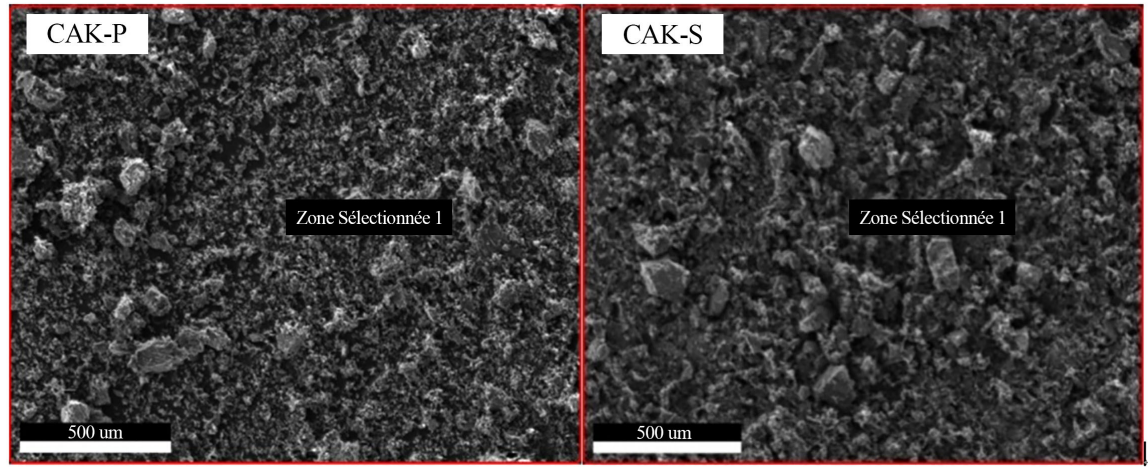

Figure 9. SEM images of the activated carbons (500 um, selected zone 1).

almost identical porosity. It should be remembered that a developed porosity increases the specific surface area of the activated carbons [31] and therefore increases the number of sites available for the fixing of pollutants during adsorption. It is also observed that both activated carbons have a heterogeneous surface.

\section{Conclusion}

In this study, a triacid and diacid were used as activating agents in the preparation of ACs using shea residues (Vitellaria paradoxa) as precursors. Central composite design was used to study the influence of preparation parameters, concentration of activating agents, carbonization temperature and residence time, on expected responses, yield and iodine number. Under the optimal conditions recommended by Statgraphic plus 5.0, thus, $5 \mathrm{~mol} \cdot \mathrm{L}^{-1}, 400^{\circ} \mathrm{C}$ and $120 \mathrm{~min}$ for CAK-P and $3.5 \mathrm{~mol} \cdot \mathrm{L}^{-1}, 700^{\circ} \mathrm{C}$ and $120 \mathrm{~min}$ for CAK-S, the iodine numbers were $709.45 \mathrm{mg} \cdot \mathrm{g}^{-1}$ and $817.36 \mathrm{mg} \cdot \mathrm{g}^{-1}$. The results of pHpzc, FTIR and Boehm titration indicate that CAK-P and CAK-S ACs prepared under these conditions are acidic. They have a microporous surface of 522.55 and $570.65 \mathrm{~m}^{2} \cdot \mathrm{g}^{-1}$ respec- 
tively for CAK-P and CAK-S. Comparative analysis of the physic-chemical characteristics shows that these two ACs are of good quality, the better one being the one activated with sulphuric acid.

\section{Acknowledgements}

The authors greatly thank assistance rendered by M. Kamdem Tamo Arnaud, Doungmo Giscard and Dr. Tagne Tiegam Rufis for their help in the characterization of activated carbons. We also thank the members of our research team for their idea and contribution throughout this manipulation and the writing of the article.

\section{Conflicts of Interest}

The authors declare no conflicts of interest regarding the publication of this paper.

\section{References}

[1] Balogoun, C.K., Bawa, M.L., Osseni, S. and Aina, M. (2015) Préparation des charbons actifs par voie chimique à l'acide phosphorique à base de coque de noix de coco. International Journal of Biological and Chemical Sciences, 9, 563-580. https://doi.org/10.4314/ijbcs.v9i1.48

[2] Vintila, T., Ioana, I., Tangne, T.R., Adriana, R.W., Calin, J. and Anagho, S.G. (2019) Residual Biomass from Food Processing Industry in Cameroon as Feedstock for Second-Generation Biofuels. Bioresources, 14, 3731-3745.

[3] Zhang, T., Walawender, W.P., Fan, L.T., Maohong, F., Daren, D. and Brown, R.C. (2004) Preparation of Activated Carbon from Forest and Agricultural Residues through $\mathrm{CO}_{2}$ Activation. Chemical Engineering Journal, 105, 53-59. https://doi.org/10.1016/j.cej.2004.06.011

[4] Mohammed-Khah, A. and Ansari, R. (2009) Activated Charcoal: Preparation, Characterization and Applications: A Review Article. International Journal of Chemical and Technology Research, 1, 859-864. https://doi.org/10.4314/bcse.v26i2.2

[5] Haykiri-Acma, H., Yaman, S. and Kucukbayrak, S. (2006) Gasification of Biomass Chars in Steam-Nitrogen Mixture. Energy Conversion and Management, 47, 1004-1013. https://doi.org/10.1016/j.enconman.2005.06.003

[6] Vargas, A.M.M., Cazetta, A.L., Garcia, C.A., Moraes, J.C.G., Nogami, E.M., Lenzi, E., Costa, W.F. and Almeida, V.C. (2011) Preparation and Characterization of Activated Carbon from a New Raw Lignocellulosic Material: Flamboyant (Delonix regia) Pods. Journal of Environmental Management, 92, 178-184. https://doi.org/10.1016/j.jenvman.2010.09.013

[7] Tchakala, I., Bawa, M.L., Djaneye-Boundjou, G., Doni, K.S. and Nambo, P. (2012) Optimisation du procédé de préparation des charbons actifs par voie chimique $\left(\mathrm{H}_{3} \mathrm{PO}_{4}\right)$ à partir des tourteaux de Karité et des tourteaux de Coton. International Journal of Biological and Chemical Sciences, 6, 461-478. https://doi.org/10.4314/ijbcs.v6i1.42

[8] Tchuifon, T.D.R., Anagho, S.G., Nche, G.N. and Ketcha, J.M. (2015) Adsorption of Salicylic and Sulfosalicylic Acid onto Powdered Activated Carbon Prepared from Rice and Coffee Husks. International Journal of Current Engineering and Technol- 
ogy, 5, 1641-1652.

[9] Idris-Hermann, K.T., Tchuifon, T.R., Doungmo, G. and Anagho, S.G. (2018) Preparation and Characterization of Activated Carbons from Bitter Kola (Garcinia kola) Nut Shells by Chemical Activation Method Using $\mathrm{H}_{3} \mathrm{PO}_{4}$; $\mathrm{KOH}$ and $\mathrm{ZnCl}_{2}$. Chemical Science International Journal, 23, 1-15. https://doi.org/10.9734/CSJI/2018/43411

[10] Bopda, A., Tchuifon, D.R.T., Nche, G.N., Doungmo, G. and Anagho, S.G. (2019) Non-Linear Equilibrium and Kinetic Study of the Adsorption of 2,4-dinitrophenol from Aqueous Solutionusing Activated Carbon Derived from a Olives Stones and Cotton Cake. African Journal of Environmental Science and Technology, 3, 365-380. https://doi.org/10.5897/AJEST2019.2717

[11] Djekonbé, P. (2019) Domestication du karité (vitellaria paradoxa c.f. gaertn) au Tchad: Evaluation de vergers et etude de la variabilite morphologique et biochimique des fruits. Thèse Doctorat/PhD, Université de Dschang, Dschang, 180 p.

[12] Djekota, C., Mouga, M., Djimramadji, A., Djelassem, B., Mbayngoné, E., Maiga, R.D., Rimgoto, K. and Noubady, D. (2014) Potentiel karité au Tchad (Vitellaria paradoxa C.F. Gaertn. Subsp. Paradoxa). Journal of Animal \& Plant Sciences, 23, 3646-3656. http://www.m.elewa.org/JAPS

[13] Annadurai, G., Babu, S., Nagarajan, G. and Ragu, K. (2000) Use of Box-Behnken Design of Experiments in the Production of Manganese Peroxidase by Phancrochate chrysosporium (MTCC 767) and Decolorization of Crystal Violet. Bioprocess Engineering, 23, 715. https://doi.org/10.1007/s004490000201

[14] ASTM D4607-94 (2006) Standard Test Method for Determination of Iodine Number of Activated Carbon. ASTM International 100 Barr Harbor Drive: United States.

[15] Goupy, J. (1996) Méthode des plans d'expériences: Optimisation du choix des essais et de l'interprétation des résultats. Edition Dunod, $34 \mathrm{p}$.

[16] Tagne, T.R.F., Ioana, I., Anagho, S.G. and Alin-cristian, M. (2019) Optimization of the Activated Carbon Preparation from Avocado Seeds, Using the Response Surface Methodology. Revista de Chimie (Bucharest), 70, 410-416. https://doi.org/10.37358/RC.19.2.6926

[17] Armineh, A., Mohammad, A.M. and Mokhtar, A. (2011) Application of Response Surface Methodology for Optimization of Reactive Blue 19 Dye Removal from Aqueous Solutions Using Pulp and Paper Sludge. Fresenius Environmental Bulletin, 20, 1-11. https://www.researchgate.net/publication/275140826

[18] Lekene, R.B.N., Ndi, J.N., Rauf, A., Kouotou, D., Placide, D.B.B., Bhanger, M.I. and Ketcha, J.M. (2018) Optimization Conditions of the Preparation of Activated Carbon Based Egusi (Cucumeropsismannii Naudin) Seed Shells for Nitrate Ions Removal from Wastewater. American Journal of Analytical Chemistry, 9, 439-463. https://doi.org/10.4236/ajac.2018.910034

[19] Atemkeng, D.C., Kamgaing, T., Tchuifon, T.D.R., Doungmo, G., Amola, A.L., Kamdem, T.A. and Anagho, S.G. (2020) Chemical Preparation and Physicochemical Characterization of Powdered Activated Carbons Based on Safou (Dacryodes edulis) Seeds. Journal of Materials and Environmental Science, 11, 896-910.

[20] Ravikumar, K., Krishnan, S., Ramalingam, S. and Balu, K. (2007) Optimization of Process Variables by the Application of Response Surface Methodology for Dye Removal Using Novel Adsorbent. Dyes and Pigments, 72, 66-74. https://doi.org/10.1016/j.dyepig.2005.07.018

[21] Arunachalam, R. and Annadurai, G. (2011) Optimizred Response Surface Metho- 
dology for Adsorption of Dyestuff from Aqueous Solution. Journal of Environmental Science and Technology, 4, 65-72.

https://doi.org/10.3923/jest.2011.65.72

[22] Maazou, S.D.B., Hima, H.I. and Mousbahou, M. (2017) Elimination du chrome par du charbon actif élaboré et caractérisé à partir dela coque du noyau de Balanites aegyptiaca. International Journal of Biological and Chemical Sciences, 11, 3050-3065. https://doi.org/10.4314/ijbcs.v11i6.39

[23] Guo, Y. and Rockstraw, D.A. (2006) Physical and Chemical Properties of Carbons Synthesized from Xylan, Cellulose, and Kraft Lignin by $\mathrm{H}_{3} \mathrm{PO}_{4}$ Activation. Carbon, 44, 1464-1475. https://doi.org/10.1016/j.carbon.2005.12.002

[24] Boehm, H.P. (1966) Chemical Identification of Surface Groups. Advances in Catalysis, 16, 179. https://doi.org/10.1016/S0360-0564(08)60354-5

[25] Danish, M., Hashim, R., Ibrahim, M.N.M. and Sulaiman, O. (2014) Optimized Preparation for Large Surface Area Activated Carbon from Date (Phoenix dactylifera L.) Stone Biomass. Biomass and Bioenergy, 61, 167-178. https://doi.org/10.1007/s00226-014-0647-y

[26] Tan, I., Ahmad, A. and Hameed, B. (2008) Optimization of Preparation Conditions for Activated Carbons from Coconut Husk Using Response Surface Methodology. Chemical Engineering Journal, 137, 462-470. https://doi.org/10.1016/j.cej.2007.04.031

[27] Kamgaing, T., Doungmo, G.F., Tchieno, M.M., Kouonang, J.G. and Ketcha, J.M. (2017) Kinetic and Isotherm Studies of Bisphenol a Adsorption onto Orange Albedo (Citrus sinensis) Sorption Mechanisms Based on the Main Albedo Components Vitamin C, Flavones Glycosides and Caortenoids. Journal of Environmental Science and Health, Part A, 52, 757-769. https://doi.org/10.1080/10934529.2017.1303315

[28] Pongener, C., Kibami, D., Rao, K., Goswamee, R.L. and Sinha, D. (2015) Synthesis and Characterization of Activated Carbon from the Biowaste of the Plant Manihot esculenta. Chemical Science Transactions, 4, 59-68.

[29] Francisco, J.S., Katie, A.C. and Matthias, T. (2018) Characterization of Micro/Mesoporous Materials by Physisorption: Concepts and Case Studies. Accounts of Materials and Surface Research, 3, 34-50. https://www.hyomen.org

[30] Ngakou, C.S., Ngomo, H.M. and Anagho, G.S. (2018) Batch Equilibrium and Effects of Ionic Strength on Kinetic Study of Adsorption of Phenacetin from Aqueous Solution Using Activated Carbon Derived from a Mixture of Ayous Sawdust and Cucurbitaceae Peelings. Current Journal of Applied Science and Technology, 26, 1-24. https://doi.org/10.9734/CJAST/2018/37300

[31] Trachi, M., Bourfis, N., Benamara, S. and Gougam, H. (2014) Préparation et caractérisation d'un charbon actif à partir de la coquille d'amande (Prunus amygdalus) amère. Biotechnology, Agronomy. Society, and Environment, 18, 492-502. 